mitotic ratio. These showed good correlation with the time of survival of the patients in months from the date of the presenting symptom. The conclusions are most promising, but it would appear that the number of mitotic cells counted, especially in the 'low-grade' malignancies, must have been extremely small. His published article on this work does not give the actual number of mitotic cells counted and therefore does not dispel statistical doubts about the method as it stands.

\section{PHYSICAL CHEMISTRY OF PROTEINS}

\begin{abstract}
A
GENERAL discussion on "The Physical Chemistry of Proteins" was held by the Faraday Society in the Department of Zoology, University of Cambridge, during August 6-8. During the meeting, introduced by Dr. J. 'l'. Edsall of Harvard University delivering the sixth Spiers Memorial Lecture, some twenty-five papers, a large proportion by foreign authors, were presented.

The programme was divided into five sections arranged in order of increasing complexity : (1) experimental techniques, (2) low molecular weight proteins, (3) high molecular weight systems, (4) protein interactions, (5) conjugated proteins. An audience of $350-400$, containing many guests from abroad, attended.

Dr. Edsall, a Fulbright Fellow of the University of Cambridge, began by reviewing the fundamental changes in our ideas on proteins since the middle twenties, when little quantitative information was available. Subsequent years saw the development of the ultracentrifuge and other physical methods by which information on the size and shape of many proteins has been obtained. Among recent developments, Dr. Edsall mentioned particularly the work of Sanger and co-workers, which has provided very complete information on the sequence of amino-acids in insulin, and the structural suggestions of Pauling, Corey and co-workers. Illustrating the state of our knowledge of the physical chemistry of proteins, Dr. Edsall dealt in detail with two important proteins - fibrinogen and serum albumin. There was general agreement that fibrinogen is an asymmetric molecule of molecular weight c. 400,000 , but many more detailed questions and the mechanism of blood clotting require further study.
\end{abstract}

Serum albumin is one of the most-studied proteins. The molecular weight was thought to be $c .69,000$ until very recently, when new experimental work has indicated that a somewhat lower value may be correct. As to the shape of the molecule, the greater part of the data is in accord with an ellipsoid of rotation of low axial ratio; details remain to be settled. While the molecule is supposed to be relatively rigid in solution, it is possible that some flexibility of the surface exists; such a property would go far towards explaining the ability of the molecule to combine with a large variety of organic and inorganic materials. Dr. Edsall considered in detail the binding of zinc and mercury atoms.

In section 1 , only the more recent advances in experimental techniques were considered. In a paper by A. Tiselius, zone electrophoresis in filter paper and other media was reviewed. Since separate bands are thus produced, the method has distinct advantages over boundary electrophoresis as a prepara- tive tool. It can readily be operated on a micro scale, at low concentrations and for a variety of materials of low molecular weight as well as macromolecules. On the other hand, electro-osmosis and adsorption may hamper quantitative work, and special measures are necessary if such effects are to be avoided. G. Weber presented a paper on the use of measurements of the polarization of fluorescence in investigating proteins in solution. Results on several protein preparations were quoted, among which those on bovine serum albumin, indicating reversible dissociation at low salt concentration and acid $p \mathrm{H}$ 's, were of especial interest. Variation of the protein concentration causes no apparent effect on the dissociation. Confirmation of these results was reported from osmotic pressure and sedimentation-diffusion studies. Several workers, however, were doubtful about this interpretation, attributing the apparent dissociation to effects of the high positive charge of the molecule under the conditions of the experiments. A final paper in this section, by J. S. Falconer, D. J. Jenden and D. B. Taylor, dealt with the application of solubility measurements to the study of complex protein solutions and to the isolation of individual proteins. In illustration, the fractionation of rat liver was considered.

The section on low molecular weight proteins began with a paper by P. Doty and G. E. Myers dealing with the thermodynamics of the association of insulin. Light-scattering measurements at acid $p H^{\prime}$ 's and varying salt concentration were used to evaluate the constants governing the equilibria between monomer, dimer and trimer over the range $20^{\circ}-40^{\circ} \mathrm{C}$. From discussion of the molecular weight of the insulin monomer, it would appear that the bulk of the kinetic data now supports the value 12,000 . In a paper by. H. Neurath and co-workers, the kinetic behaviour of trypsin and related molecules was considered. When trypsin is examined under conditions favourable to enzymatic activity, the sedimentation constant, varying with the age and $p H$ of the protein solution, corresponds with autolysis of the protein. On the other hand, when the enzyme is stable and inactive, no such anomalies are observed. Trypsinogen and the diisopropylfuorophosphate derivative similarly show normal behaviour. A molecular weight of 24,000 was reported for the inactive proteins. G. E. Perlmann presented an electrophoretic study of enzymatically modified ovalbumin and casein. The reactions considered were: (l) the ovalbumin -plakalbumin transformation in which carboxyl groups are liberated, and (2) the dephosphorylation of ovalbumin, plakalbumin and casein. In each case, characteristic changes in electrophoretic mobilities and patterns were produced; electrophoresis is thus a useful tool in following enzyme changes involving charged groups. E. Barbu and M. Joly dealt with the transformation of certain globular into fibrous proteins by moderate heating, salt effect, or high pressure. Several physical methods were utilized, and the authors suggested that end-to-end aggregation rather than unfolding of the molecules is responsible for the fibrous products obtained. Denaturation was treated in the light of the results obtained. In the following discussion, several workers directed attention to denaturation reactions which would be difficult to explain by end-to-end aggregation and for which chain unfolding is the more likely explanation.

In section 3, the first paper, by $\mathrm{P}$. Johnson and W. E. F. Naismith, reported experimental results 
on reversible association-dissociation reactions occurring in the conarachin fraction of the groundnut globulins. Higher ionic strengths and $p \mathrm{H}$ favour the dissociated form, whereas low ionic strength and $p \mathrm{H}$ 's near the isoelectric point give large proportions of association products. Light scattering, which shows the rapid establishment of equilibrium, confirms sedimentation results; but electrophoresis gives no indication of the reactions occurring. In the discussion, attention was directed to the possible effects of rapid equilibria on the behaviour of moving boundaries. In a paper by $\mathrm{S}$. Shulman, the effects of certain ions and neutral molecules on the conversion of fibrinogen to fibrin were considered. Many compounds, under similar conditions, are found to delay clotting by at least twenty-four hours (inhibition), though this action is reversible. Others cause much less delay in clotting (retardation). Correlation between the structures of the different compounds and their inhibitory action was attompted. Miss E. M. Petri and A. J. Staverman dealt with the electrochemical propertics of lupin seed protein. The isolation and chemical analysis of the protein were described; membranes prepared from it were investigated with respect to their electrochemical behaviour. The effect of various chemical modifications has similarly been studied. Considerable discussion of the nature of the reactions involved followed.

The remaining papers in section 3 discussed muscle and its proteins. G. Hamoir described an electrophoretic study of the muscle structural proteins -myosin, actin, actomyosin and tropomyosinrabbit and carp muscles mainly being used. Dr. Hamoir considers that his results demonstrate the infrequent occurrence of interaction between the different components ; but in the discussion following, it appeared that other workers do not agree that electrophoretic diagrams exclude such effects. In part 1 of a paper on energetics and molecular mechanisms in muscle action, M. Morales and J. Totts summarized experimental data on thermoelastic properties of myosin threads, and on light scattering and kinetic measurements on actomyosin - adenosine triphosphate systems. This was interpreted in terms of a theory which assumes that the elastic particles contract by virtue of the increased entropy resulting but extend by reason of electrostatic forces. In part 2, by T. L. Hill, several simplified though possible models of the basic elastic element were considered, and the detailed properties were calculated by statistical thermodynamical treatments. T.-C. Tsao and $\mathrm{K}$. Bailey presented a paper on aspects of polymerization of proteins of the muscle fibriltropomyosin, myosin and actin. Tropomyosin and actin react very differently to the addition of electrolyte. Myosin, of greater constancy in its molecular weight, is thought by them to contain two types of sub-unit, a cyclic and an open-chain unit, each requiring special conditions for isolation. A detailed discussion of these papers followed.

Prof. L. Pauling introduced the proceedings of section 4 with a speculative discourse on the different types of association phenomena which are likely to follow mild modification of a protein system. For extensive association to occur, a single molecule must be provided with at least two active points on its surface; head to tail aggregation would then produce a helix the character of which would be determined by the relative positions of the reactive points on the protein surface. Different types of packing of such helices, stabilized by appropriate forces, as well as their interpenetration in various ways, were further possibilities. This approach, though speculative (and termed 'snip and fiddle' by one speaker) may well be basic to many aggregation phenomena involving proteins. A paper by E. J. Cohn and co-workers dealt with the interaction of plasma proteins at physiological $p H$ with metals, alkaline earths, carbohydrates, and formed elements of the blood. Much of the information presented is now being utilized in the Harvard laboratory in new fractionation procedures for the plasma proteins. I. M. Klotz and $J$. Ayers reviewed earlier work on the binding by serum albumin of organic anions and cations and described new work with related neutral molecules. The results indicate that the protein undergoes configurational changes with change of $p H$ or electrical charge. Low hydroxy-amino-acid content was discussed as a cause of the binding ability of serum albumin, and, in confirmation, the binding of $\alpha$ - and $\beta$ casein is found to be appreciable though lower than that of serum albumin. B. S. Harrap and J. H. Schulman presented work on the influence of salt on the size and shape of a complex between sodium dodecyl sulphate and bovine serum albumin. Using viscosity and light-scattering measurements in salt solution, definite complexes of low asymmetry were indicated; in absence of salt no definite complexes occurred, though uncoiling of the molecules was indicated. E. Gorter and L. Nanninga reported a detailed study by physical and other methods of the interaction of several proteins with heparin, suramin and chondroitin sulphuric acid. The interaction occurs between the $\mathrm{SO}_{3}{ }^{-}$groups of the latter compounds with positive groups on the protein, and is therefore very dependent on $p H$. The action of heparin as an anticoagulant was discussed in the light of these results. M. Fleming and D. O. Jordan presented results of an electrophoretic study of calf thymus deoxypentose nucleoprotein and of tobacco mosaic virus. Under certain conditions, the nucleoprotein dissociates into two fractions, and it is postulated that one fraction is protein, leaving a conjugate richer in nucleic acid. 'The final paper in this section, by R. J. Goldberg and J. W. Williams, was concerned with the antigen-antibody reaction. Adapting the statistical mechanical treatment of three-dimensional polymer condensation to the combination between antigen and antibody, predictions of the position of inhibition zones and antibodyantigen ratios in precipitates have been compared with experiment.

Section 5 began with a review of conjugated proteins by Prof. M. Stacey. Concentrating on complexes of proteins with nucleic acid and carbohydrates, Prof. Stacey mentioned particularly virus and bacterial nucleoproteins, the transforming principle of pneumococcus, mucopolysaccharide blood-group factors and certain recently studied mucoproteins. F. B. Seibert dealt particularly with tuberculin proteins, prepared from unheated tuberculin filtrates as well as live bacillary bodies. A study of their amino-acid content, electrophoretic mobilities, ultraviolet absorption, nucleic acid and carbohydrate content was considered in relation to their biological potencies. E. J. Ambrose and J. A. V. Butler presented data on the swelling of nucleoprotein films in the presence of various salts. The concentration of salts required to prevent swelling is of the same order as that required to precipitate the nucleoprotein from solution. Infra-red absorption and double 
refraction of partially orientated films is compatible with parallel arrangement of $\beta$-polypeptide chains in the direction of stretching, the planes of the purine and pyrimidine rings lying perpendicular to this direction. Other structures are, however, possible. K. Meyer presented evidence for the existence of protein complexes of hyaluronic acid and chondroitin sulphates from hyaline cartilage and connective tissue. Reversibly formed polar complexes with the protein are suggested except in the case of chondroitin sulphate from connective tissue, which is stably linked to protein. A. G. Ogston and J. E. Stanier have isolated the hyaluronic acid complex from synovial fluid by ultrafiltration, since they believe that precipitation affects the physical properties. Such preparations contain 27 per cent protein, the removal of which caused a change in properties. Physical methods have indicated that the complex exists as a random coil of nearly spherical shape and large hydration. Its biological function was discussed.

\section{OBITUARY}

\section{Sir Richard Gregory, Bart., F.R.S.}

"MY particular mission has been to make men of science conscious of their power and influence in shaping eivilized life." So wrote Sir Richard Gregory in his message of farewell published in Nature of January 7,1939 , when he resigned from the editorial chair which he had occupied with such distinction for so many years. Throughout his long life, which came to a close on September 15, his interest in science for its own sake, and equally for the appreciation by others of its value and significance for humanity, was a driving force which brooked no obstacle, and happily that interest was sustained to the end.

Richard Arman Gregory was born in Bristol on January 29, 1864. His first post was as laboratory assistant at Clifton College. From there he passed on to the Royal College of Science, London, where he met several of the men who were to exert such an influence on him, as he on them, in later yearsH. G. Wells, T. H. (later Sir Thomas) Holland, and especially Sir Norman Lockyer. He became research assistant to Sir Norman, and from that period arose a lasting love for astronomy and astrophysics. At this time he began to contribute occasional notes to Nature, of which Sir Norman had been editor since its foundation in 1869, and in 1893 he was appointed sub-editor of the journal. This marked a turning point in his career. Until then, his first interest had been astronomy, with the general feeling for science as a whole and its applications to human welfare. From then on, this second interest grew in intensity, and as the years went by and Lockyer left Nature more in the hands of his young colleague, it became his guiding influence. In articles, in lectures and addresses, he was never tired of developing and enlarging this theme.

While Lockyer had established the general lines on which Nature was conducted, and built up its reputation, Gregory did not hesitate to introduce innovations. Thus to make the journal a living force in the nation and the whole world of science, he felt it was necessary to publish more than occasional leading aricles; and in due course-but not without a certain amount of opposition-he got his way, and the leading article expressing a point of view on matters scientific or their significance became a regular feature of the journal. For some fifteen or sixteen years of this period, he virtually conducted the journal himself, carrying out administrative duties as well as the normal tasks of sub-editor. During his annual holidays, he remained in touch by post. In 1919, Lockyer retired, and Gregory took over the full responsibility which he had already been exercising for some years. His work continued, for he was a true working editor, marking manuscripts for the printer and seeing the journal through the press week by week with all the attention to detail such work demands.

There was never an editorial committee; neither was there even a special panel of reviewers. The entire scientific world, both at home and abroad, has always been Nature's willing advisers and critics. Thus, through this valuable freedom from committee control and especially through the integrity and fearlessness of its editor, was Sir Richard able to contribute very largely towards making the journal what it is-a journal of science, published for men of science, written by men of science. He accepted the saying that 'a good editor wears out the soles of his shoes before the seat of his pants' ; and was always ready to consider fresh views even if they conflicted with those accepted.

In spite of the heavy load of work which he assumed in this way, this did not by any means exhaust Gregory's seemingly unlimited store of energy. A short period of teaching in the Dockyard School at Portsmouth earlier on, coupled with his own personal experiences, persuaded him that there was a dearth of good school science text-books. Starting with astronomy and what used to be termed 'physiography', he began writing text-books which quickly made their mark for their accuracy and practical approach, and their appreciation of students' difficulties. Alone and in association with others, notably the late H. E. Hadley and A. T. Simmons, he wrote and edited a number of such books, many of which are still in use both in Great Britain and overseas after passing through several editions. By his sustained interest in scientific developments he was able to keep these books in line with scientific progress, even within the past two years.

This interest in education also showed itself in his activities in the British Association. He was one of the leaders in the formation of Section L (Education) of the Association, and for its first ten years served as one of its secretaries or its recorder. In 1922 he was president of the Section. In 1899 he helped to found the School World, which was later incorporated in the Journal of Education, and he was joint editor until 1938.

Almost as a by-product of his work for Nature was his book "Discovery : or the Spirit and Service of Science" published in 1916, in which he outlined in his characteristically clear and simple style some leading scientific discoveries, using them to illuminate his perennial theme, the worth of science.

From an early date, Gregory had been in considerable demand as a lecturer. On the platform he divided his attention between astronomy and the social implications of science; and as the years went by he identified himself more and more with the latter topic. Here may be mentioned his work for the British Science Guild. This body, formed to promote the appreciation and application of scientific 